EGU21-10386

https://doi.org/10.5194/egusphere-egu21-10386

EGU General Assembly 2021

(c) Author(s) 2021. This work is distributed under

the Creative Commons Attribution 4.0 License.

\title{
Co-Designing Mobile Applications for Data Collection: A Comparative Evaluation of Co-Design Processes in the Project "Nachtlicht-BüHNE"
}

Friederike Klan ${ }^{1}$, Christopher C.M. Kyba ${ }^{2}$, Nona Schulte-Römer ${ }^{3}$, Helga U. Kuechly ${ }^{2}$, Jürgen Oberst $^{4,5}$, Anastasios Margonis ${ }^{5}$, and Marius Hauenschild ${ }^{5}$

${ }^{1}$ German Aerospace Center (DLR), Institute of Data Science, Jena, Germany

${ }^{2}$ GFZ - German Research Centre for Geosciences, Potsdam, Germany

${ }^{3}$ Helmholtz Centre for Environmental Research (UFZ), Leipzig, Germany

${ }^{4}$ German Aerospace Center (DLR), Institute of Planetary Research, Berlin, Germany

${ }^{5}$ Institute of Geodesy and Geoinformation Science, Technical University Berlin, Berlin, Germany

Data collection via mobile software applications is playing an increasingly important role in Citizen Science projects. When developing such applications, it is important to consider both the requirements of the scientists interested in data collection and the needs of the citizen scientists who contribute data. Citizens and participating scientists therefore ideally work together when conceptualizing, designing, and testing such applications (co-design). In this way, both sides scientists and citizens - can contribute their expectations, desires, knowledge, and engagement at an early stage, thereby improving the utility and acceptance of the resulting applications. How such a co-design process must and can be meaningfully designed depends very much on (1) the interests, skills and background knowledge of the project participants, (2) the complexity and type of the data collection methodology to be implemented, and (3) the time, financial and legal conditions under which the software is developed.

In our contribution, we address this point. We present two methodologies that enable the joint design and implementation of software applications for mobile data collection in citizen science projects. These represent quite different best practice approaches that emerged during the development of mobile applications on the topics of light pollution and meteor observation in our Citizen Science project Nachtlicht-BüHNE. We examine and compare the resulting methods with respect to their suitability for use under different conditions and thus provide future citizen science projects based on participatory developed mobile applications with decision support for the design of their co-design approach. We shed light on the two co-design methods with respect to the following criteria, among others: possible types of contributions by volunteers, requirements on expertise and knowledge of the contributors, flexibility of the method with respect to changing requirements, possibilities with respect to the design of complex data collection methods, costs incurred and time required for the implementation of the methodology. 